\title{
Extreme Risk Protection Orders and Persons with Dementia in the State of Washington
}

J Gen Intern Med 36(12):3885-7

DOI: $10.1007 / \mathrm{s} 11606-020-06273-4$

(c) Society of General Internal Medicine 2020

\section{INTRODUCTION}

Extreme Risk Protection Order (ERPO) laws allow for restricting firearm access among individuals who are at substantial risk of harming self or others. ERPOs are court orders requested by "Petitioners" to prompt the "Respondent" to surrender firearms and to prohibit purchase of new firearms. Additionally, ERPOs prevent renewals or requests for new concealed carry licenses. ${ }^{1}$ With appropriate evidence of concerning behavior, family members, household members, or law enforcement officers in Washington may request an ERPO. $^{2}$

Particularly vulnerable to firearm injury are the millions of persons with dementia (PWD) living in the USA. Between 40 and $60 \%$ of this population has a firearm in home. ${ }^{3}$ PWD may exhibit combative behavior; in addition, depression is among the most common symptoms, putting them at high risk for suicide. ${ }^{3,4}$ One retrospective study found that among veterans with dementia, the majority of suicides $(73 \%)$ involved the use of a firearm. ${ }^{5}$

There is scant evidence for guidance ${ }^{6}$ related to firearm safety among PWD. Unfortunately, firearms often remain accessible beyond a point that is safe for the individual, household members, and visitors such as children. In this case, ERPOs may be a useful tool to remove firearms when there is evidence of danger. There have been no studies reported on dementia and ERPOs. We describe a case series of ERPO filings due to dangerous behavior in the context of age-related cognitive decline, dementia, or Alzheimer disease in Washington between December 2016 and May 2019.

\section{METHODS}

We identified all ERPO filings and associated county court records in Washington between December 8, 2016, and May 10, 2019. ${ }^{2}$ We narrowed our sample to include

This article has not been published or presented in any format.

Received July 21, 2020

Accepted September 25, 2020

Published online October 16, 2020 cases with a mention of cognitive decline, dementia, or Alzheimer disease in the narrative of ERPO petitions or associated court documents. We report brief narrative summaries of each of the cases, ascertained through publicly available court data. The study was approved by the University of Washington Institutional Review Board.

\section{RESULTS}

During the study period, 237 individuals had an ERPO filed for them as a respondent; of those respondents, 9 (4\%) were PWD, all of whom were men. One of the Respondents was Black and eight were White. Two had family members as Petitioners; the rest were law enforcement entities. ERPOs were granted for six, which resulted in the prohibition of firearms for one year. Five respondents had contact with law enforcement and/or adult protective services due to violent or erratic behavior prior to the ERPO petition filing. All but one of the individuals kept a firearm on their person or in an unsecured location; one individual kept firearms in a locked safe. A brief narrative summary of the nine cases is presented in Table 1. Common themes in the nine cases included a pattern of paranoid behavior, delusions/hallucinations, history of domestic violence, alcohol/substance abuse, and suicidal ideation.

\section{DISCUSSION}

This case series of dementia-related ERPOs in Washington suggests a pattern of firearms being unsafely stored and accessible to PWD with advanced disease and/or individuals exhibiting aggressive and paranoid behavior. For patients with mild cognitive impairment or dementia, providers should assess for the presence of firearms and discuss this with patients and their families, as recommended by a number of professional societies. To maintain autonomy, such guideline-based interventions can use shared decision-making to the extent appropriate within the context of disease progression. The timing of such conversations should be considered as early as possible to address the potential for increased suicide risk immediately after diagnosis, ${ }^{5}$ as well as to protect against further cognitive decline prior to engagement in decisionmaking. In the absence of such interventions, ERPOs 
Table 1 Summary Details ${ }^{a}$ of Dementia-Related ERPO Cases in Washington from December 8, 2016, to May 10, 2019

\begin{tabular}{|c|c|}
\hline $\begin{array}{l}\text { Respondent } \\
\text { ID }\end{array}$ & Summary $^{\mathbf{a}}$ \\
\hline 1 & $\begin{array}{l}\text { The Petitioner was a family member of a Respondent. The Petitioner expressed concern over the Respondent's ability to safely } \\
\text { handle firearms due to dementia. Caregivers felt uncomfortable with the Respondent brandishing pistol to "show" them that he is } \\
\text { armed. The Respondent kept loaded gun on person. His family called } 911 \text { and expressed concern for his safety and caregiver's } \\
\text { safety. In a final encounter with law enforcement, he expressed a desire for suicide by police. The ERPO was dismissed for reasons } \\
\text { that we were not able to determine. }\end{array}$ \\
\hline 2 & $\begin{array}{l}\text { The Petitioner was a family member, having filed an ERPO on a Respondent with both mental health concerns and possible } \\
\text { dementia. The Respondent had multiple guns both in a gun safe and unsecured. He made open threats of violence toward neighbors. } \\
\text { The Petitioner filed ERPO with documentation from a physician of the Respondent's inability to safely handle firearms. A judge } \\
\text { denied ERPO (standard of evidence not met) and the Respondent was able to keep firearm despite deteriorating cognitive condition. }\end{array}$ \\
\hline 3 & $\begin{array}{l}\text { The Petitioner was law enforcement, filing an ERPO on a Respondent who was suffering from Alzheimer disease with recurrent } \\
\text { delusions and paranoia as well as potential alcoholism. The Respondent claimed that intruders were entering his residence and stated } \\
\text { that he armed himself with firearms to fend them off. Immediately preceding the ERPO, law enforcement was dispatched to the } \\
\text { house, responding to an elderly assistance alarm as well as a self-reported shooting, from which bullet holes were discovered in the } \\
\text { residence. Law enforcement removed firearms from premises. The ERPO was granted. }\end{array}$ \\
\hline 4 & $\begin{array}{l}\text { The Petitioner was law enforcement entity, filing an ERPO on a Respondent who was suffering from potential dementia and } \\
\text { alcoholism, with a history of domestic violence. The Respondent had called } 911 \text { several times reporting break ins over the course of } \\
\text { the prior months. Immediately preceding filing of the ERPO, law enforcement was called to do a welfare check at the Respondent's } \\
\text { residence. He had multiple unsecured and loaded handguns and rifles on a shelf in his residence. The caregiver expressed concern } \\
\text { that the Respondent could shoot them or others. The ERPO was granted. }\end{array}$ \\
\hline 5 & $\begin{array}{l}\text { The Petitioner was law enforcement, filing an ERPO on a Respondent who, in addition to suffering from a recent diagnosis of } \\
\text { dementia/Alzheimer disease, had a history of violent behavior, suicidal ideation, and mental health concerns. The Respondent's } \\
\text { family described erratic and confused behavior coupled with unsafe storage of firearms, violent outbursts, unprompted brandishing of } \\
\text { his firearm, and not recognizing familiar people. Due to suicidal ideations, he was emergently detained at an area hospital where he } \\
\text { was evaluated. The ERPO was granted. }\end{array}$ \\
\hline 6 & $\begin{array}{l}\text { The Petitioner was law enforcement, filing an ERPO on a Respondent who suffered from dementia. The Respondent reportedly told } \\
\text { neighbors, who called the police, that he had shot himself when he had not. He also expressed a desire for police to shoot him. The } \\
\text { Respondent lived in a home with over a dozen firearms, in addition to firearms present from family members living in the home. His } \\
\text { doctor provided a letter describing dementia diagnosis caused by alcoholism and/or Alzheimer disease. The Respondent had made } \\
\text { threats of violence against the doctor after revocation of his driver's license. The ERPO was granted. }\end{array}$ \\
\hline 7 & $\begin{array}{l}\text { The Petitioner was a law enforcement, filing an ERPO on a Respondent who suffered from Alzheimer disease. He had also made } \\
\text { threats against anyone coming to his home with intentions of removing him, saying he would shoot them. His dementia was } \\
\text { exasperated by ongoing alcoholism, contributing to hostility. The Petitioner stated that apart from dementia, the Respondent had a } \\
\text { long history of ongoing domestic violence. The ERPO was granted. }\end{array}$ \\
\hline 8 & $\begin{array}{l}\text { The Petitioner was law enforcement, filing an ERPO on a Respondent who suffered from suspected dementia. The Respondent's } \\
\text { wife called } 911 \text { after he threatened to kill himself. Multiple firearms were kept unsecured in night stand. The Respondent may be } \\
\text { lying about access to firearms, one of which he claims was stolen. The full ERPO was denied. }\end{array}$ \\
\hline 9 & $\begin{array}{l}\text { The Petitioner was law enforcement, filing an ERPO on a Respondent who has a history of violence and vascular dementia with } \\
\text { behavioral disturbance. The Petitioner was called to the house for a reported burglary, and when they arrived, the Respondent } \\
\text { threatened them with a gun. The Respondent had a recent diagnosis of cancer, ongoing marital problems, and a history of alcoholism. } \\
\text { Over the decade preceding the ERPO, the Respondent had several complaints from neighbors for threatening, suspicious, or } \\
\text { harassing encounters. The full ERPO was granted. }\end{array}$ \\
\hline
\end{tabular}

${ }^{a}$ Narratives were reported so that factual details were shuffled between cases. All summaries are representative of details from actual cases, while respecting anonymity

provide a tool for concerned family members and law enforcement to safeguard PWD and the public for a oneyear duration with potential to renew annually in Washington state. Our study is limited because it is a narrative review of available documentation, on a small number of cases mentioning dementia or possible dementia in one state, and therefore may not be representative of other cases of ERPOs filed for PWD. In the absence of data on cognitive functioning, these cases may not have been clinical diagnoses, but were based on petitioner report and/or supporting documentation. Additional research on firearm access in this vulnerable population and on the usefulness of ERPO is critically warranted.

Laura C. Prater, PhD, MPH, MHA ${ }^{1,2}$

Miriam J. Haviland, $\mathrm{PhD}, \mathrm{MSPH}^{1}$

Frederick $P$. Rivara, $M D, M P H^{1,2,3}$

M. Alex Bellenger, MA, MPA ${ }^{1}$
Lauren Gibb, $\mathrm{MPH}^{1}$

Ali Rowhani-Rahbar, $\mathrm{MD}, \mathrm{PhD}, \mathrm{MPH}^{1,2,3}$

${ }^{1}$ Harborview Injury Prevention and Research Center, University of Washington,

Seattle, WA, USA

${ }^{2}$ Department of Epidemiology, School of Public Health, University of Washington,

Seattle, WA, USA

${ }^{3}$ Departments of Pediatrics, School of Medicine, University of Washington,

Seattle, WA, USA

Corresponding Author: Laura C. Prater, $\mathrm{PhD}, \mathrm{MPH}, \mathrm{MHA}$; Harborview Injury Prevention and Research Center, University of Washington Seattle, WA, USA (e-mail: lprater@uw.edu).

Funding Financial support was received from the state of Washington. 


\section{Compliance with Ethical Standards:}

The study was approved by the University of Washington Institutional Review Board.

Conflict of Interest: The authors report no conflicts of interest.

\section{REFERENCES}

1. Seattle.gov. Extreme Risk Protection Orders. https://www.seattle.gov/ police/need-help/erpo\#: :text=Home Need Help\%3F-, Extreme Risk Protection Orders, person poses a significant danger. Updated 2020. Acessed July 2020.

2. Rowhani-Rahbar A, Alex BM, Gibb L, Chesnut H, Lowry-Schiller M, Gause E, Haviland M, Rivara F. Extreme Risk Protection Orders in Washington. Ann Intern Med. 2020;Online First.
3. Morgan ER, Gomez A, Rivara FP, Rowhani-Rahbar A. Household firearm ownership and storage, suicide risk factors, and memory loss among older adults: results from a statewide survey. Ann Intern Med. 2019;171(3):2202.

4. Erlangsen A, Zarit SH, Conwell Y. Hospital-diagnosed dementia and suicide: A longitudinal study using prospective, nationwide register data. Am J Geriatr Psychiatry 2008;16(3):220-8.

5. Seyfried LS, Kales HC, Ignacio RV, Conwell Y, Valenstein M. Predictors of suicide in patients with dementia. Alzheimers Dement 2011;7(6):56773.

6. Betz ME, McCourt AD, Vernick JS, Ranney ML, Maust DT, Wintemute GJ. Firearms and dementia: Clinical considerations. Ann Intern Med 2018;169(1): 47-49.

Publisher's note Springer Nature remains neutral with regard to jurisdictional claims in published maps and institutional affiliations. 